\title{
SILDENAFIL IS SAFE AND EFFECTIVE FOR THE TREATMENT OF LOWER URETERIC STONE WITH NO MAJOR SIDE EFFECT
}

\author{
$K C S R^{1^{*}}$, Timilsina $B R^{1}$, Upadhyay $H P^{2}$, Devkota $G^{3}$, Shah $R^{1}$, Lamichhane $N^{1}$
}

\section{Affiliation}

1. Lecturer, Department of Urology, College of Medical Science \& Teaching Hospital, Nepal

2. Lecturer, Department Community medicine, College of Medical Science \& Teaching Hospital, Nepal

3. MPHScholar, Patan Hospital, Nepal

\section{ARTICLE INFO}

\section{Article History}

Received : 12 October, 2018

Accepted : 2 December, 2018

Published : 31 December, 2018

(C) Authors retain copyright and grant the journal right of first publication with the work simultaneously licensed under Creative Commons Attribution License CC - BY 4.0 that allows others to share the work with an acknowledgment of the work's authorship and initial publication in this journal.

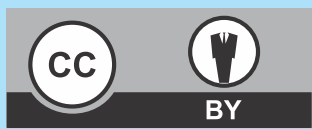

ORA 90

DOI: $10.3126 /$ bjhs.v3i3.22190

$$
\begin{gathered}
\text { * Corresponding Author } \\
\text { Dr Sudeep Raj KC } \\
\text { Lecturer } \\
\text { Department of Urology } \\
\text { College of Medical Science, Teaching Hospital, Nepal } \\
\text { Email: sudeeprkc786@gmail.com } \\
\text { ORCID ID: https://orcid.org/0000-0002-6584-3768 }
\end{gathered}
$$

\section{Citation}

KC SR, Timilsina BR, Upadhyay HP, Devkota G, Shah R, Lamichhane N. Sildenafil is Safe and Effective for the Treatment of Lower Ureteric Stone with no Major Side Effect. BJHS 2018;3(3)7:560-564.

\section{ABSTRACT}

\section{Introduction}

Urolithiasis is one of the most common disease of the urinary tract. Prevalence of urinary stones in a life time is approximately $1 \%$ to $15 \%$.Peak age of incidence is 30 years. Male are more commonly affected than female about 2 to 3 times. At the time of presentation $20 \%$ of the calculi are found in the ureter, among which $70 \%$ are located in the distal third of the ureter.

\section{OBJECTIVE}

To study the effect of sildenafil citrate on passage of stone from distal ureter.

\section{METHODOLOGY}

This is the Quasi experimental study performed in College Of Medical Sciences, Chitwan, Nepal, from February 2017 to February 2018 for a period of one year. First 100 patients of urolithiasis were selected and divided into two groups with the help of lottery method Group A and Group B. In group A we had patient on placebo and in group $B$ we had patient receiving sildenafil $50 \mathrm{mg}$ once daily and for the period of two weeks.

\section{RESULTS}

The mean \pm standard deviation of stone size was $7.01 \pm 1.70 \mathrm{~mm}$ for treatment group and $6.85 \pm 1.56 \mathrm{~mm}$ for placebo group ( $p>0.64$ ). The stone expulsion rate was $74.5 \%$ for treatment group and $41.7 \%$ for placebo group $(P<0.001)$. Mean \pm standard deviation of expulsion time was $7.6 \pm 3.49$ days for treatment group and $10.25 \pm 3.12$ days for placebo group $(\mathrm{P}<0.008)$. Mean \pm standard deviation of VAS was $3.49 \pm 1.300$ for treatment group and $6.77 \pm 1.308$ for placebo group $(\mathrm{P}<0.0001)$.

\section{CONCLUSION}

Medical Expulsive Therapy (MET) for lower ureterolithiasis with sildenafil during conservative treatment period is safe and effective as demonstrated by the absence of serious side effects and increased stone expulsion rate with early time.

\section{KEYWORDS}

Lower ureteric stone, Medical Expulsive Therapy, Sildenafil 


\section{INTRODUCTION}

Urolithiasis is one of the most common disease of the urinary tract. Prevalence of urinary stones in a life time is approximately $1 \%$ to $15 \%$. Peak age of incidence is 30 years. Male are more commonly affected than female about 2 to 3 times. ${ }^{1}$ At the time of presentation $20 \%$ of the calculi are found in the ureter, among which $70 \%$ are located in the distal third of the ureter. ${ }^{2}$ Spasm induced by ureter due to stone will interfere with its expulsion. So, by reducing spasm and gaining normal peristaltic activity the stone expulsion chance increases.

Fifty percentage of the ureteric calculi will pass spontaneously in time but size of the calculi is the key factor for its success. Calculi less than $5 \mathrm{~mm}$ in size will pass spontaneously and decreases significantly as the size increases. There is only $20 \%$ chance of stone expulsion if stone size is greater than 8 mm in size. ${ }^{3}$

Most commonly used agents for medical expulsion therapy is alpha-1 adrenergic blocker.

Many studies have proven that tamsulosin increases the stone expulsion rate and decreases the expulsion time. So, it is extensively used. ${ }^{4,5}$

Nowadays, phosphodiesterase-5 (PDE5) inhibitors has shown some promise in stone expulsion. Phosphodiesterases are enzymes that regulate intracellular cyclic nucleotide metabolism cyclic guanosine monophosphate [cGMP], cyclic adenosine monophosphate [cAMP]) which helps in the relaxation and contraction of the muscles. Some of the studies have shown that phosphodiesterase-5 relax muscles of the lower ureter. ${ }^{6}$

Sildenafil, a PDE5 inhibitor, causes local release of NO, causes increased levels of cGMP which further causes relaxation of the smooth muscles of ureter. ${ }^{7}$ Sildenafil is drug which is used in erectile dysfunction(ED) and sometimes even in lower urinary tract symptoms due to benign enlargement of prostate (BEP), its role in distal ureteric calculi has not been well practiced in Nepal. On the other hand, tamsulosin is well accepted and used widely in our part of the world. This study is aimed to analyse the safety and efficacy of Sildenafil in distal ureteric calculi and also to compare the efficacy of Sildenafil with placebo group.

\section{METHODOLOGY}

This is a quasi-experimental study performed in College Of Medical Science, Chitwan, Nepal, from February 2017 to February 2018 and ethical clearance was taken from institutional review board. Inclusion criteria were patient over 16 years presented to outpatient department in the department of urology, $<10 \mathrm{~mm}$ calculi located in distal ureter confirmed with NCCT, CT Urography or USG. Exclusion criteria were patient with history of heart diseases, high or low blood pressure, active peptic ulcer, urinary tract infection which was confirmed with urine culture and sensitivity, severe pain not controlled with NSAIDS, acute or chronic renal failure, single functioning kidney, congenital ureteric anomalies, calculi in bilateral ureter, multiple calculi in the ureter, calculi in mid and proximal ureter, risk factor to priapism (e.g. sickle cell anaemia, multiple myeloma or leukaemia)

Sample size for treatment group was calculated using the formula,

$$
n=\left(\frac{r+1}{r}\right) \frac{(\bar{p})(1-\bar{p})\left(Z_{\mathrm{b}}+\mathrm{Z}_{\mathrm{a} / 2}\right)^{2}}{\left(\mathrm{p}_{1}-p_{2}\right)^{2}}
$$

Where, $p 1=$ prevalence in treatment group $=67.3 \%$, $\mathrm{p}_{2}=$ prevalence in comparison group $=40.4 \%, \bar{p}=\left(p_{1}+p_{2}\right) / 2,1$ : $r=$ required ratio (1:1).

The level of significance was kept at $\alpha=0.05$, the power was kept at $1-\beta=0.8, Z$ value was taken single sided as the alternative hypothesis is set as use of sildenafil is better than no treatment. Sample size for comparison group was calculated as $\left(r^{*} n\right)$. Sample size in each group was calculated to be 47 after taking non response rate as $10 \%$, which was then increased to 50 . Hence total sample size was taken as 100.

100patient were divided into two groups Group A and Group $B$ with the help of lottery method. In group A we had patient on placebo and in group $B$ we had patient receiving sildenafil 50 once daily for the period of two weeks. Both group of patient received tab diclofenac $50 \mathrm{mg}$ for three days then as per requirement by the patient for colicky pain. Patient were asked to drink plenty of water and filter urine with thin net to look for stone whether or not it is excreted. Patient were asked to follow up in OPD on weekly basis and whenever required. The record for analgesic use, adverse effect of the drugs, and number of hospital visit for pain and expulsion time for stone were recorded. Data were collected and filled in proforma. Data were analyzed by using the SPSS16.0. Discrete variables were evaluated by chi-square test and continuous variables by unpaired Student t-test. All statistical tests were based on two-tailed probability, and a p-value $<0.05$ was considered statistically significant.

Expulsion of stone was confirmed with the help of history by asking patient to pass urine through filter and reconfirmed with USG. In some patient who still showed hydronephrosis in USG scan were subjected to NCCT to confirm expulsion. Side effect of drugs were also recorded like headache, postural hypertension, backache and gastritis.

Primary objective of this study was to check for stone expulsion and secondary objective was to check for number of colicky pain, analgesic required and drug side effect. Patient who failed for stone expulsion were subjected to surgery.

\section{RESULTS}

Group A (placebo group) included 29 male and 19 female with mean age of $30.93 \pm 13.94$, while group B (sildenafil group) included 29 male and 18 female with mean age of $29.08 \pm 12.0$. No statistical difference were observed in patient age between two groups $\mathrm{P}=0.49$ neither with regards to sex difference $p=0.576$ using chi square test. 
Mean stone size was $6.85 \pm 1.56 \mathrm{~mm}$ range from 4.5 to $10 \mathrm{~mm}$ in group $A$ and.7.01 $\pm 1.70 \mathrm{~mm}$ range from 4.5 to $10 \mathrm{~mm}$ for group $B$. There was no difference between the average diameter of the stone between two group $p=0.642$ using independent t test.

The stone expulsion rate was $41.7 \%$ (20 out of 48 ) for group A and $74.5 \%$ ( 35 out of 47 ) for group B. The stone expulsion rate is statistically significant for the treatment group. $\mathrm{P}=0.001$.

Group B showed a statistically significant advantage in term of the stone expulsion rate ( $p$ value $<0.001$ ) and mean expulsion time $(\mathrm{P}=0.008$ i.e. $\mathrm{p}$ value $<0.05)$ so there is statistically significant difference between the two groups. Table (1).

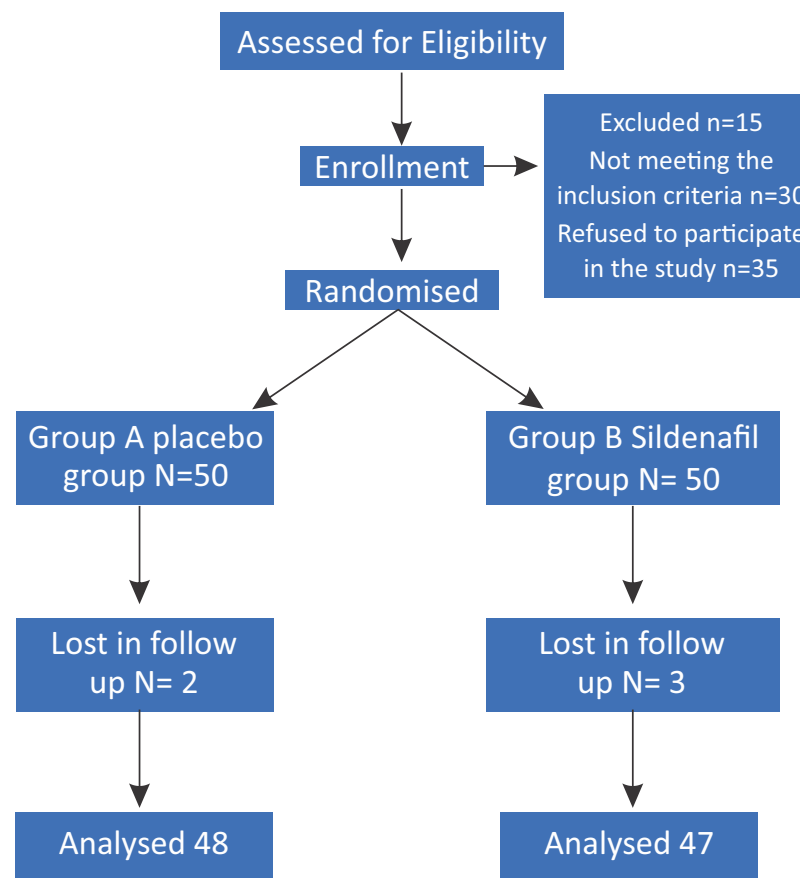

Figure 1: Trail profile

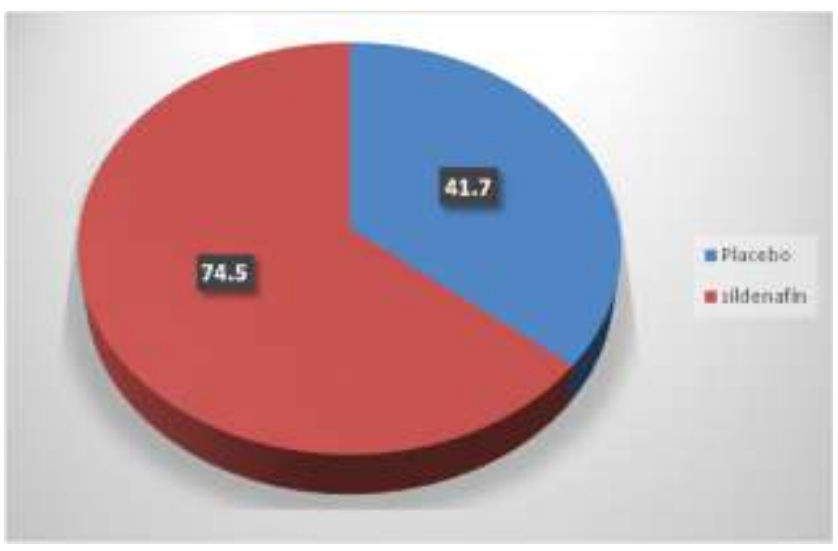

Figure 2: Percent of Expulsion in two groups

Patient in group B had lower VAS (visual analogue scale) $3.49 \pm 1.300$ than that of patient in group $A$ who had $6.77 \pm$ $1.308(p<0.0001)$. Table (1)Stone PassesThe mean number of analgesic use during therapy was $7.56 \pm 1.62$ for group $A$ and $3.48 \pm 1.10$ for group $B$ (figure 5 ), showing significantly less analgesic use in group $B,(P<0.0001)$

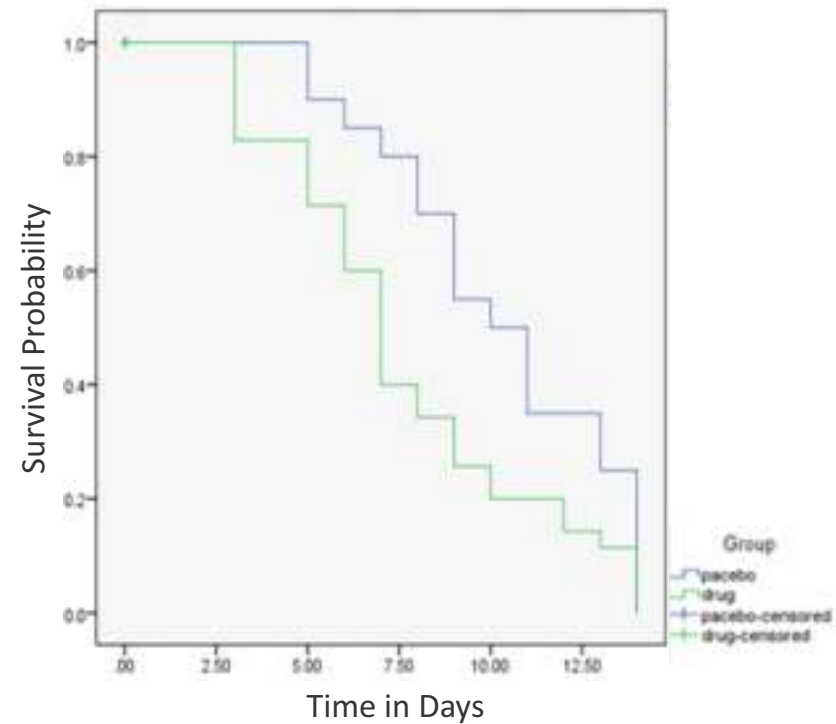

Figure 3: Kaplan-Meier curve comparing the rate of spontaneous passage of ureteric stones in both groups

The Kaplan-Meier curve showed that the stone passage rate was significantly higher in the sildenafil citrate group vs the placebo group ( $P=0.028$; figure 3 )

Studying the factor predicting stone passage with univariable analysis showed that patient receiving sildenafil citrate was the only factor that significantly affected the stone passage. Cox proportional hazard model showed that patient receiving sildenafil citrate was the only independent factor that had significant impact on stone passage with HR1.68(95\% Cl 0.96-2.96; P=0.046)

Table 1: Different Parameters between the Two Groups

\begin{tabular}{|c|c|c|c|}
\hline Parameter & $\begin{array}{c}\text { Group A } \\
\text { Placebo }\end{array}$ & $\begin{array}{c}\text { Group B } \\
\text { Sildenafil Cirtate }\end{array}$ & P Value \\
\hline Mean stone size & 6.856 & 7.012 & 0.642 \\
\hline Rate of Expulsion & $41.7 \%$ & $74.5 \%$ & 0.001 \\
\hline Mean hour of expulsion & 10.25 days & 7.63 days & 0.001 \\
\hline VAS for pain & 6.77 & 3.49 & $<0.001$ \\
\hline Mean Analgesic Used & 7.56 & 3.48 & $<0.001$ \\
\hline
\end{tabular}

In the sildenafil citrate group patient reported with headache with was treated with acetaminophen, 3 patient complained of unnecessary erection. It was identified that all patient who expelled their stones did that within 14 days of oral Sildenafil 50mg treatment start. Total of 40 patient failed on MET in both group were subjected to URS after 15 days of treatment plan.

\section{DISCUSSION}

Large volume of distal ureteric calculi will pass spontaneously. Some of the impacted stone and even the stone that pass can cause some complications like hydronephrosis, complicated urinary tract infection and renal dysfunction; which requires treatment as per complication. EDU urolithiasis guideline state that stone size more than $10 \mathrm{~mm}$ in size requires URS, but for smaller stone size less then $10 \mathrm{~mm}$ both URS and ESWL is preferred. ${ }^{9}$ Choice of treatment further depends upon patient choice and availability of the 
instrument. Although URS is preferred option by most of the surgeon; there are many disadvantage like requirement of general or regional anaesthesia need for hospital admission, and there are many local complications like trauma to the ureter, ureter avulsion and in late run stricture. Nowadays with the availability of sophisticated instrument like flexible ureterorenoscopy and use of narrow calibre instrument these rate have decreased significantly.

ESWL is also a safe method of treatment for ureteral stone, which is used since late 1980. Patient who are subjected to ESWL does not require hospitalization, general or regional anaesthesia, and even returned to work immediately after the procedure. Main drawback of this procedure is they are less effective in harder stone.

MET is widely practiced by most of the surgeon as an initial treatment option of stones of different size. Till date there are different drug used for MET like alpha blockers, anticholinergics, trigliserilnitrate, steroids. These drug not only increases the rate of expulsion but also decreases the episode of renal colic.

Understanding the pathophysiology well has implemented the use of MET as conservative treatment option. Many randomized trials have supported alpha blocker as effective drug for MET. $^{12-15}$ Sildenafil is a PDE5 inhibitor that act on ureter by relaxing its smooth muscle by increasing cGMP. The role of PDE5 is well established for ED and BEP but its role in the ureteric calculi is still in the preliminary stage in practice but there are many studies showing itself effectiveness.

Shokeir et al in 2016 studied in 100 cases out of which there were 4 drop out, 47 and 49 patients were analysed in both of the group placebo and sildenafil; respectively. Groups were comparable for age and stone characteristics. Spontaneous expulsion occurred in 19 of 47 patients (40.4\%) in the placebo group and in 33 of $49(67.3 \%)$ patient in the sildenafil citrate group $(P=0.014)$. The mean time to stone expulsion was significantly shorter in the sildenafil citrate group $(P<0.001)^{16}$

Altogether 85 patients were studied by Hari bahadur kc in 2016, 41 in group $A$ and 44 in group B, were enrolled in study. The patients' average age was $31.72 \pm 12.63$ years, and the male-to-female ratio was 1.5:1. Demographic profiles, stone size, and baseline investigations were comparable between the 2 groups. The stone expulsion rate was significantly higher in the tadalafil group than in the tamsulosin group (84.1\% vs. 61.0\%, $p=0.017)$. $^{17}$

Hassan et al in 2011 studied 60 patients which showed 93.3\% expulsion rate compared to pacebo group which was only $63.3 \%$, mean expulsion time was 5.5 days and with tadalafil group comparted with 8.84 days in the placebo group. ${ }^{18}$

Our study also had similar age group compared to other study but has less rate of expulsion compared to hassan et al and kc et al may be because they compared other drugs of same group tadalafil who has longer half-life then sildenafil. In our study where sildenafil was used as a drug of choice and have slightly better result than placebo.

Sildenafil citrate significantly improve the stone expulsion rate compared to placebo group with not much of side effect.

\section{CONCLUSION}

PDE5 inhibitor is the effective treatment option in distal ureteric calculi compared with placebo group with high expulsion rate and better mean expulsion time. Compared to placebo PDE5 inhibitor decreases incidence of colicky pain and the amount of analgesic required. However high quality trails and multicentre study with large number of sample size needs to be conducted to support the conclusion of our study.

\section{RECOMMENDATION}

Sildenafil citrate can be used as a drug for medical expulsion therapy for distal ureteric calculi with minimal side effect. However high quality trails and multicentre study with large number of sample size needs to be conducted.

\section{LIMITATION OF STUDY}

Limitation of this study is small number of sample size and one centre study.

\section{CONFLICT OF INTEREST}

There is no conflict of interest in this article.

\section{FINANCIAL DISCLOSURE \\ None}

\section{REFERENCES}

1. Pearle MS, Y L. Urinary lithiasis: etiology, epidemiology, and pathogenesis in. 10th ed. Wein AJ, Kavoussi LR, Novick AC, Partin AW, Peters CA, editors. Philadelphia: Saunders Elsevier2012. 1257$86 \mathrm{p}$.

2. Ahmed AF, Al-Sayed A. Tamsulosin versus alfuzosin in the treatment of patients with distal ureteral stones: prospective, randomized, comparative study. Korean J Urol 2010;51:193-7.

3. Ueno A, Kawamura T, Ogawa A, H T. Relation of spontaneous passage of ureteral calculi to size. Urology. 1977;10:544-6.

4. Singh SK, Agarwal MM, S S. Medical therapy for calculus disease. BJU Int 2011;107:356-68.

5. Wang CJ, Huang SW, CH C. Efficacy of an alpha1 blocker in expulsive therapy of lower ureteral stones. J Endourol. 2008;22:41-6.

6. Gratzke C, Uckert S, Kedia G, Reich O, Schlenker B, M S. In vitro effects of PDE5 inhibitors sildenafil, vardenafil and tadalafil on isolated human ureteral smooth muscle: a basic research approach. Urol Res 2007;35:49-54.

7. Gratzke C, Uckert S, Reich O, Schlenker B, Tilki D, M S. PDE5 inhibitors. A new option in the treatment of ureteral colic? Urologe A 2007; 46:1219-23.

8. Hübner WA, Irby P, ML S. Natural history and current concepts for the treatment of small ureteral calculi. Eur Urol 1993;24:172-6. 
9. Tiselius HG, Ackermann D, Alken P, et al. Guidelines on urolithiasis. European Association of Urology [website]. 2008 Mar. http:// www.uroweb.org/fileadmin/user_upload/Guidelines/ Urolithiasis. pdf. Accessed January 28, 2014.

10. Parker BD, Frederick RW, Reilly TP, Lowry PS, ET B. Efficiency and cost of treating proximal ureteral stones: shock wave lithotripsy versus ureteroscopy plus holmium: yttrium-aluminumgarnet laser. Urology. 2004;64:1102-6.

11. Hong YK, DS P. Ureteroscopic lithotripsy using Swiss lithoclast for treatment of ureteral calculi: 12-years experience. J Korean Med Sci 2009;24:690-4.

12. Seitz C, Liatsikos E, Porpiglia F, Tiselius HG, U Z. Medical therapy to facilitate the passage of stones: what is the evidence? Eur Urol. 2009;56:455-71.

13. Hollingsworth JM, Rogers MA, Kaufman SR, Bradford TJ, Saint S, JT W. Medical therapy to facilitate urinary stone passage: a metaanalysis. Lancet. 2006;368:1171-9.
14. Parsons JK, Hergan LA, Sakamoto K, C L. Efficacy of alpha-blockers for the treatment of ureteral stones. J Urol. 2007;177:983-7.

15. Sigala S DM, Milanese G, Fornari S, Faccoli S, Palazzolo F. Evidence for the presence of alpha1 adrenoceptor subtypes in the human ureter. Neurourol Urodyn 2005;24:142-8.

16. Shokeir AA, Tharwat MA, Abolazm AE, A H. Sildenafil citrate as a medical expulsive therapy for distal ureteric stones: A randomised double-blind placebo-controlled study. Arab J Urol. 2016;14:1-6.

17. KC HB, Shrestha A, Acharya GB, Basnet RB, Shah AK, PM S. Tamsulosin versus tadalafil as a medical expulsive therapy for distal ureteral stones: A prospective randomized study. Clin Uro. 2016;57:351-6.

18. Hasan HF , Jaffal WN , HA A-H. The Role of Tadalafil in Lower Ureteric Stone Expulsion. Iraqi Postgrad Med J. 2011;10:24-32. 